\title{
A Multimedia Medical Expert System for Human Diseases Diagnosis
}

Ahmed Kh. Ameen
Baydaa I. Khaleel

Baydaa_ibraheem@yahoo.com

\author{
Department of Computer Science, \\ College of Computer Science and Mathematics \\ University of Mosul, Mosul, Iraq
}

Accepted on: 31/01/2021

Received on: 04/01/2021

\begin{abstract}
With the great expansion and development of computer science and its systems. Its applications are used in most areas of life, which facilitated the solution of many simple and complex issues, as it was used in multiple fields, including the medical field, where computer applications were designed to help the specialist doctor in his work and reduce the time in diagnosis. In this research, an expert system is built, which is one of the artificial intelligence techniques, using the advanced (forward) sequencing algorithms also called data-directed inference, and the algorithm. Backward (backward) sequence, also called target-directed inference, to diagnose the most common diseases to which a person is exposed. It is supported by multimedia, which includes (text, images, audio, and video) to reach a solution to the problem through dialogue with the user and rely on the stored knowledge as a base on which the inference engine represented by the two algorithms to reach to solutions, instructions and recommendations to diagnose the disease and give the appropriate treatment. These solutions are given to users in several forms using multimedia (text, pictures, audio and video) and this system is used by people who cannot reach a doctor or hospital for any reason. This system consists of major parts, which are the knowledge base that organizes the collection of facts the laws and the inference engine, which in turn include the Forward Chaining and Backward Chaining algorithms.

These diseases in order to reach a diagnosis of the disease with high accuracy, and this leads to reducing medical errors. The proposed system can be used as a substitute for the doctor in diagnosing some diseases in general and some diseases in particular. Which is useful in cases where the doctor is absent due to natural conditions or emergency situations, or when it is difficult for the patient to reach hospitals or health centers.
\end{abstract}

Keywords: artificial intelligence, advanced (forward) sequencing algorithms, Backward (backward) sequence.

$$
\begin{aligned}
& \text { نظام خبير طبي متعدد الوسائط لتشخيص أمراض الإنسان }
\end{aligned}
$$

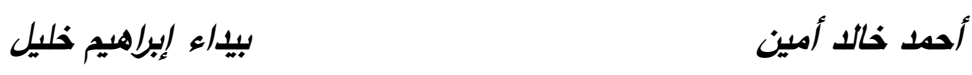

$$
\begin{aligned}
& \text { قسم علوم الحاسوب، كلية علوم الحاسوب والرياضيات } \\
& \text { جامعة الموصل، الموصل، العرقاق علومالب }
\end{aligned}
$$

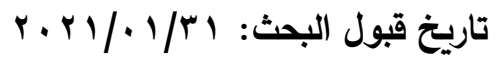

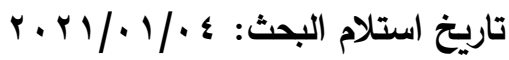




\section{الملخص}

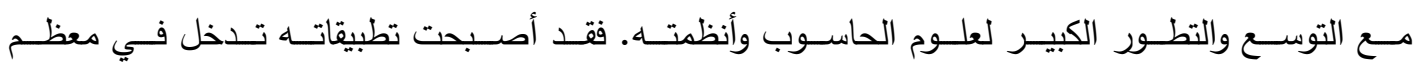

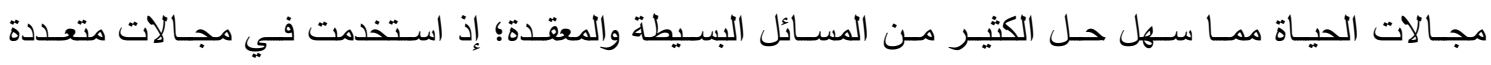

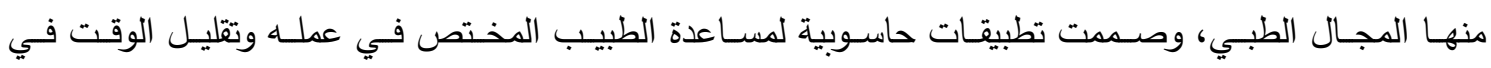

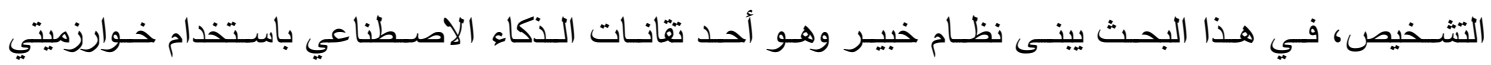

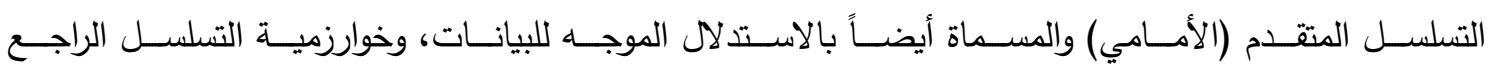

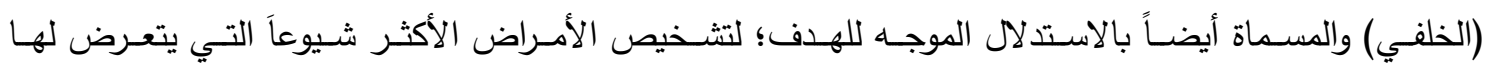

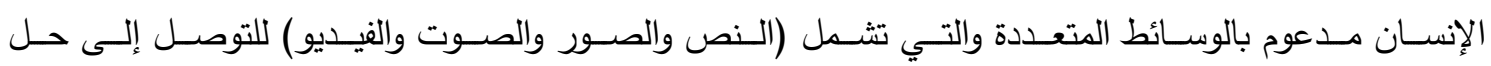

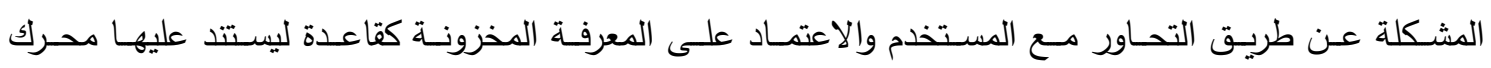

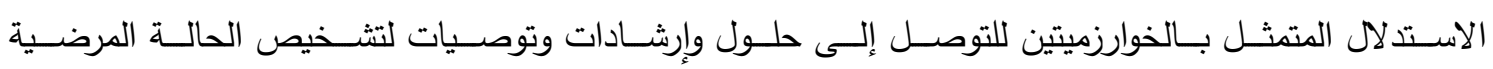

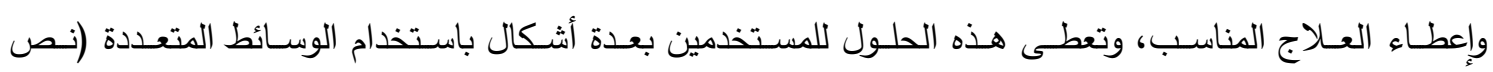

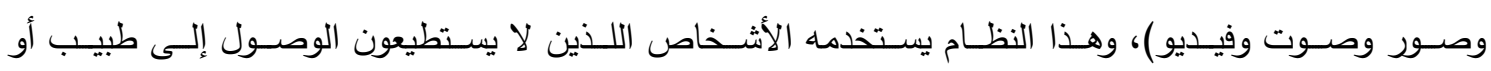

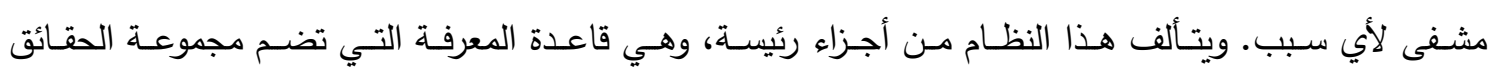

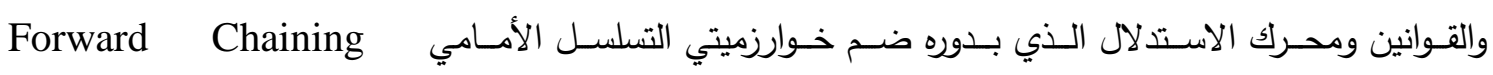
والتسلسل الراجع Backward Chaining. لقد بنيت قاعدة المعرفة في هذا النظام من الأمراض، أما القوانين فبنيت من أعراض تلك الأمراض للتوصل إلى تشخيص المرض بدقة عالية، ويؤدي ذلك إلى تقليل الأخطاء الطبية، ويمكن استخدام النظام المقترح ليكون

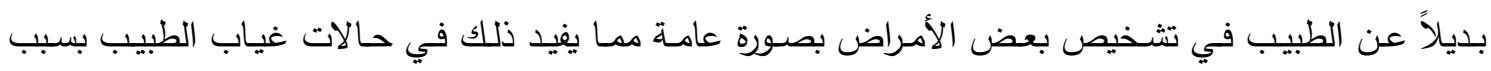
الحـالات الطبيعيـة أو الحـالات الطارئـة أو عندما يصـعب على المـريض الوصـول إلى المستثـفيات أو المراكز الصحية.

الكلمـات المفتاحيـة: الذكاء الاصـطناعي، خـوارزميتي التسلسل المتقدم (الأمـامي)، وخوارزميـة التسلسل الراجـع

1. 1

علم الذكاء الاصطناعي يكافح لبناء الذكاء المفيد بحد ذاته والفعّال في عدة مجالات في حياتتا التي أصبحت

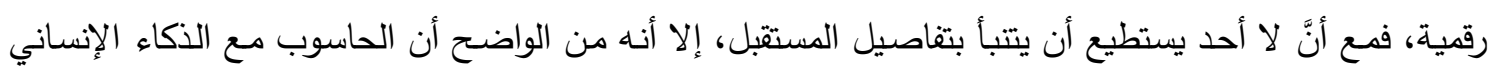

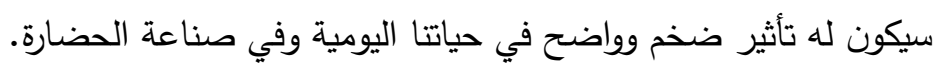

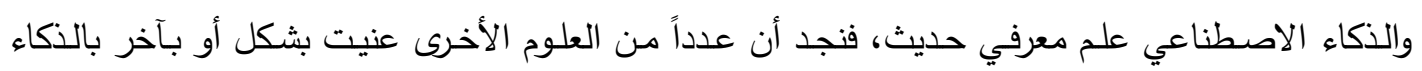

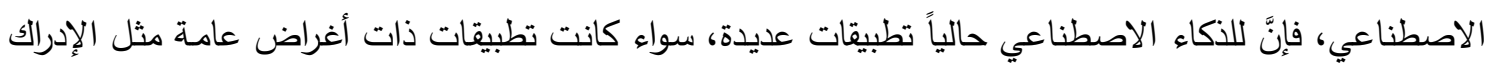
والتعليل المنطقي، أو كانت مهمات ذات غرض خاص مثل لعب الثطرنج أو التثخيص الطبي، غالباً فإنَّ الخبراء

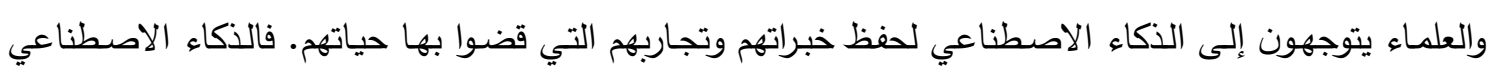
مجال عالمي يصلح لجميع التوجهات[1]. 
استخدم الذكاء الاصطناعي بنجاح في مجموعة واسعة من المجالات من بينها النظم الخبيرة ومعالجة اللغات

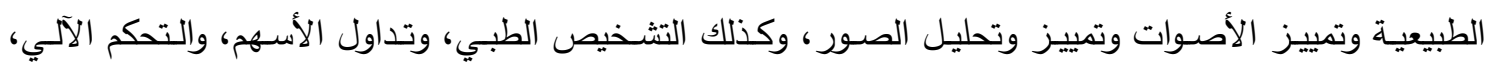
والقانون، والاكتثافات العلمية، وألعاب الفيديو ولعب أطفال ومحركات البحث على التحلى الإنترنت، في كثير من الأحيان

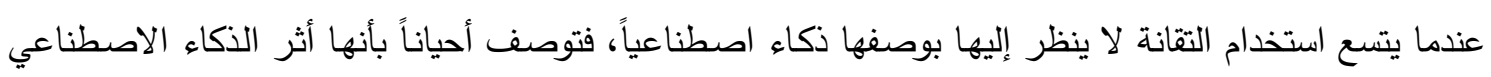

وللأنظمة الخبيرة أهمية كبيرة في كونها تهدف إلى حل المشاكل المتعلقة بمجالات متخصصـة التي تتطلب

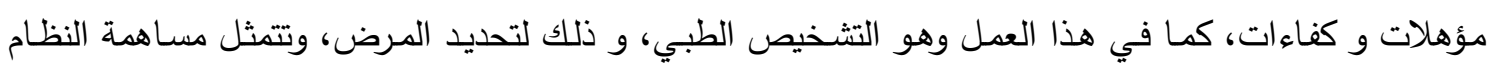

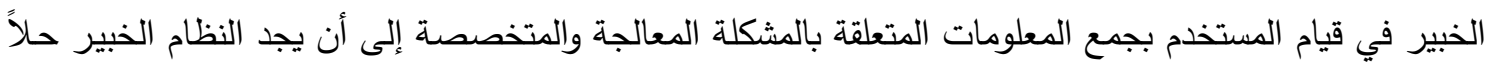

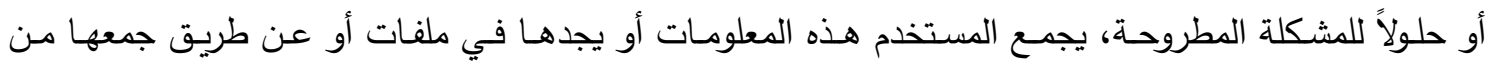
المتخصصين بذلك، وفي هذا البحث استخدم خوارزميتي التسلسل المتقدم والراجع المعتمدة على البحث بعمق لبن لبناء نظام خبير طبي متعدد الوسائط لتشخيص الأمراض الأكثر شيوعاً التي يتعرض لها الإنسان.

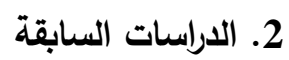

لقد اعتتى المختصون في مجالي الطب والحاسوب بتطبيق الأنظمة الخبيرة في الطب بصورة عامـة وفي

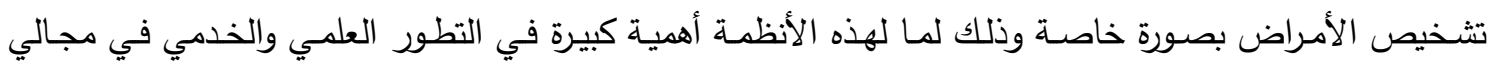
الحاسوب والطب على حد سواء، هنالك العديد من الدراسات السابقة في تطبيق الأنظمة الخبيرة نذكر منها:

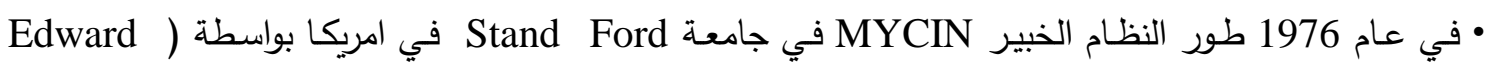
(Shortliffe في أطروحته لنيل شهادة الدكتوراه، وقد صمم هذا النظام لمسـاعدة الأطباء في تثخيص البكتريـا ومعالجتها التي تسبب أمراض الدم والتهاب أغشية السحايا وهو يقدم نصائح استثارية عن دخول الجرثومة للدم وهي العدوى التي تتضمن إصـابة الدم بالبكتريا، والتهاب السحايا (Bacteremia) التي تتضمن التهاب الأغشية التي تغطي الدماغ والحبل الثوكي. وقد أشـارت الأبحاث إلى أنـه أعطى العـلاج المقبول بنسبة 69\% من الحالات، وكان هذا أفضل من أداء خبراء الأمراض المعدية الذين يستخدمون المعايير نفسها [3]. • في الثمانينات من القرن العشرين شهدت الأبحاث اهتماماً جديداً وذلك للنجاح التجاري الذي شهدته الأنظمة الخبيرة التي تحاكي المهارات، وتعتمد على المعرفة التحليلية لواحدة أو أكثر من خبراء البشر ، ولكن تباطؤ التطور التكنولوجي الالكتروني وعدم اتباع خوارزميات متطورة أدى إلى تباطوئها، كونها تحتاج إلى مساحات خئسئ خزنية كبيرة

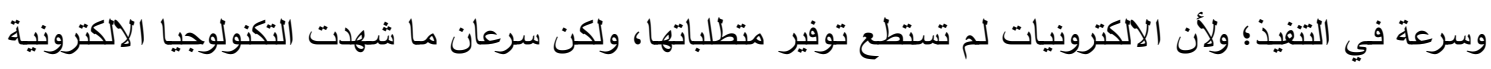

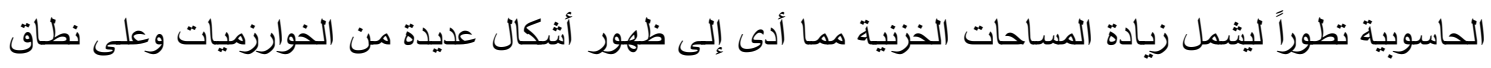
واسع وفي شتى المجالات [4]. • في 2005 قدم Razavan c. Bunuesu and Raymond j. Mooney، طريقة التعلم الآلي لتحديد العلاقات

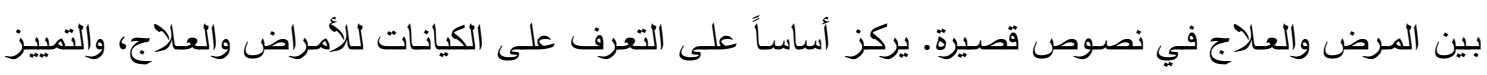

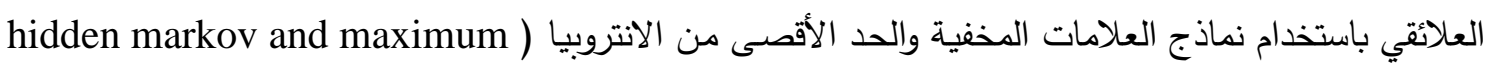

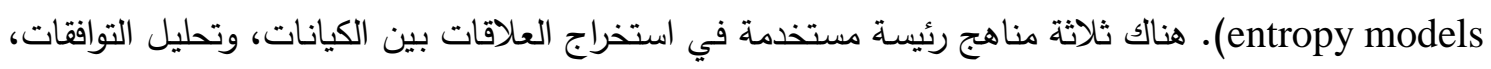
والأساليب القائمة على القواعد[5]. 
• وفي عام 2006 أثبتت البحوث حول العالم بأن الذكاء الاصطناعي يتناقض تجريبياً عند القيام بمجهود تفكير معتبر أمام مشكلة مقدة؛ إذ تحتاج إلى ذكاء أقل من نتيجة الحالة المعقدة نفسها عند أخذ قرار سريع وعفوي لكن التهن الدراسات الحديثة أثتتت عكس ذلك؛ كون الذكاء لا يرتبط بالجهد الذهني ولا بحجم الحالة ومدى تعقيدها؛ فصناعة إنهاء

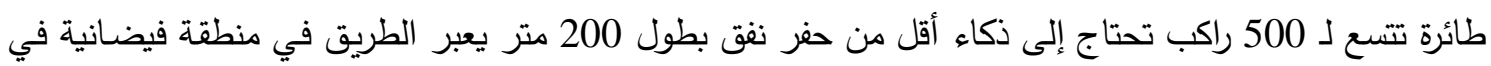
المدينة [6].

• وفي عـام 2012 قـام كـل مـن ( Opara و Eze ) ببنـاء نظـام خبيـر لتشـخيص الأمـراض ووصـف الـدواء

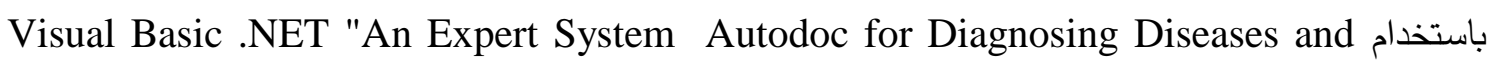
واعطاء ومع وهو نظام يشخص الأمراض التي تصيب الجنس البشري وإعطاء وصفة الدواء المناسب للمرض الذي يشخصه هذا النظام، وقد طبق هذا النظام على حالات مرضية عديدة،

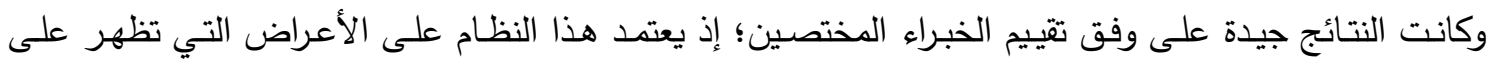
المريض لتشخيص الأمراض بدقة [7]. • في عام 2013 قام الباحث عمر أحمد حامد ببناء نظام خبير لتثخيص الأمراض الباطنية؛ إذ صمم الباحث البرنامج لكي يستقبل شكوى المريض (الأعراض التي يعاني منها المريض)، ثم يقوم البرنامج بتكوين قائمسة بكل

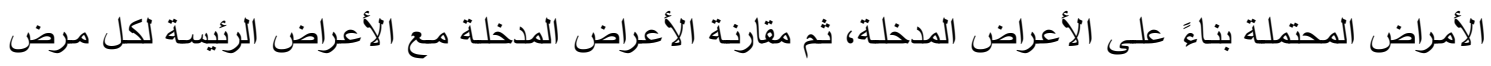

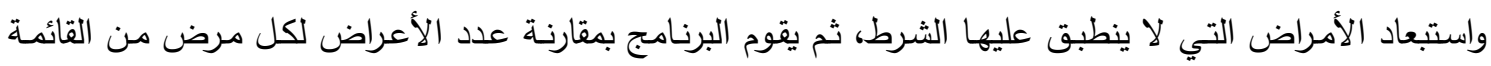

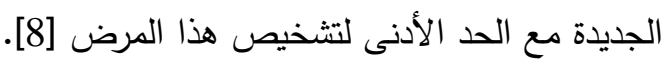
• في عام 2018 قام الباحث إبراهيم نضير ببناء نظام خبير لغرض إعطاء تشخيص لبعض الأمراض عن طريق

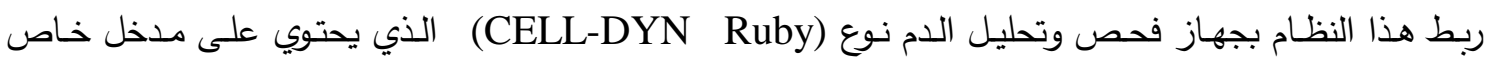
للكومبيوتر ، يقسم النظام إلى عدة وحدات أهمها وحدة إدخال التاريخ الطبي للمريض، وحدة المراجعة المنهجية،

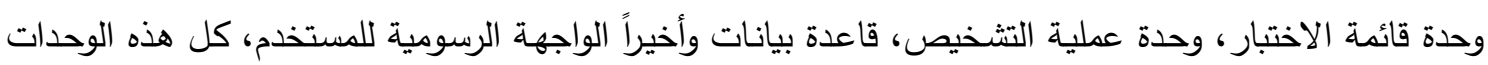

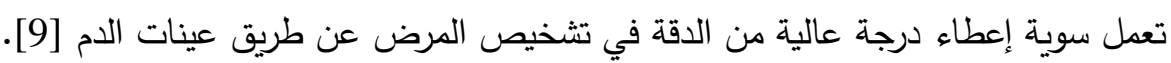
•وفي عام 2020 بعض الدراسـات المتعلقة بالذكاء الاصطناعي ساعدت في الطب الإشعاعي كما في دراسـة ستانفورد والتي نتج عنها خوارزمية يمكنها الكثف عن الالتهاب الرئوي بطريقة أفضل من مختصي الأشعة [10].

3. هيكلية الأنظمة الخبيرة

تتكون النظم الخبيرة من ثلاثة أجزاء رئيسة هي:

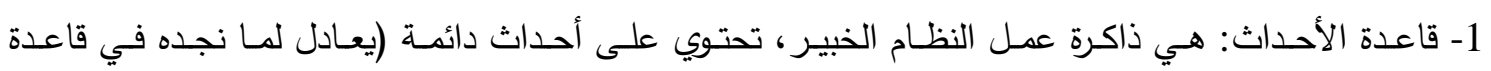
المعطيات)، وأحداث خاصة بالمشكلة المطروحة التي نسميها أيضاً معطيات.

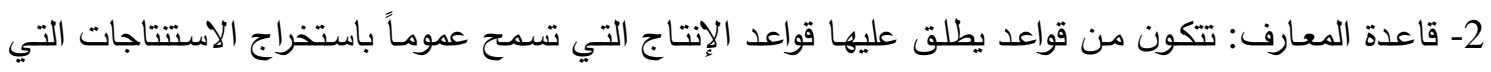

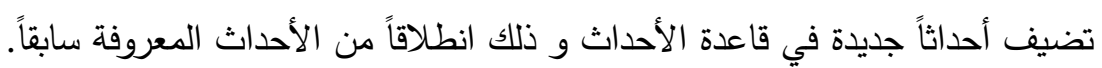

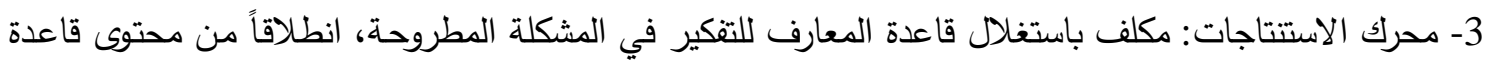

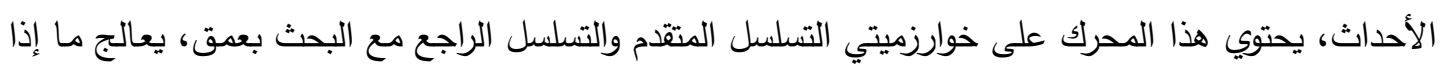
كانت فرضية قاعدة ما محققة بالأحداث الموجودة في قاعدة الأحداث[11]، وهيكلية النظم الخبيرة يمكن تمثيلها في الثكل(1) الآتي: 


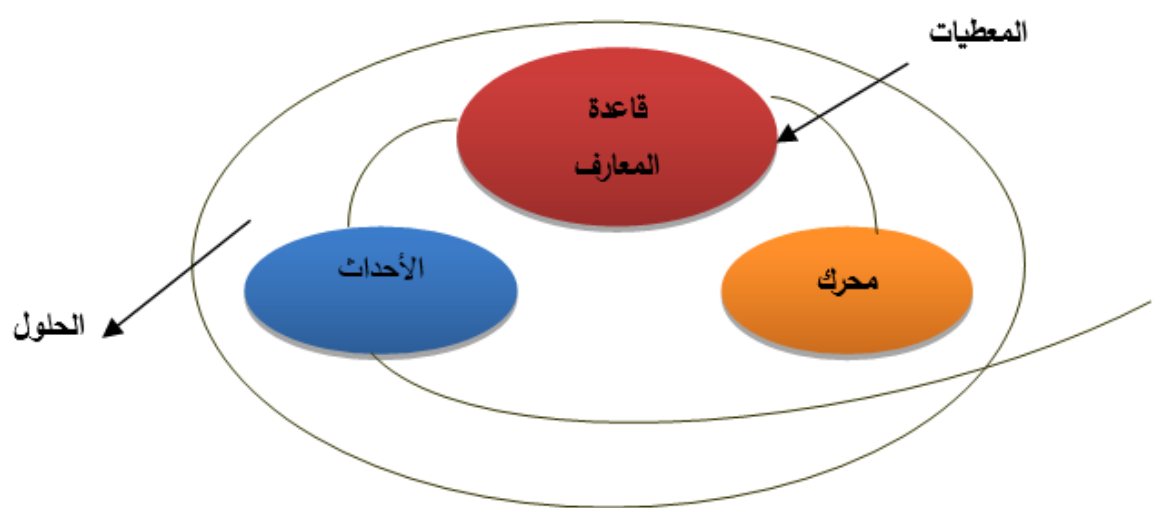

الثكل (1) تمثيل هيكل الأنظمة الخبيرة

4. خوارزميات التسلسل المتقدم والتسلسل الراجع

(Forward Chaining) (التسلسل المتقدم

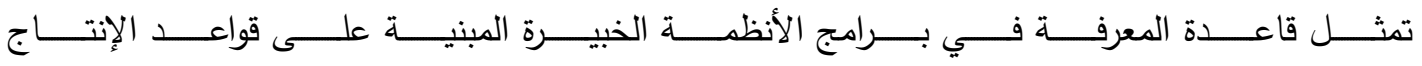

بواسطة مجموعة قواعد وهذه القواعد تقارن بمجموعة من الحقائق بالمسألة (Rule Based Expert System) المعينة المراد إيجاد الحل لها. [12]

إن هذه الطريقة تتضمن فحص جزء الشرط من القاعدة لتحديد أي منها صحيح أو خاطئ؛ إذا كان الثرط صحيحاً عندئذٍ سينفذ الفعل (Action) أو الأجزاء.

وتستمر هذه العملية إلى أن يتم الوصول إلى الحل أو الوصول إلى النهاية[13]، أي: إنه يلاحظ أن محرك النك

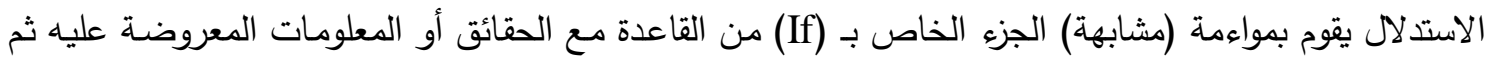

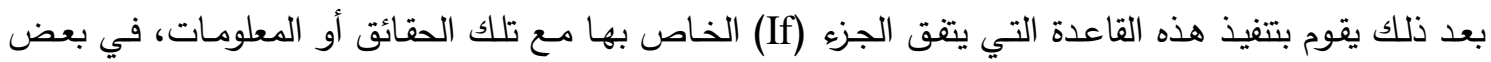
الأحيان قد يؤدي تتفيذ قاعدة من القواعد (الحكم بالخبرة) إلى تعديل مجموعـة من الحقائق في قاعدة المعرفة.

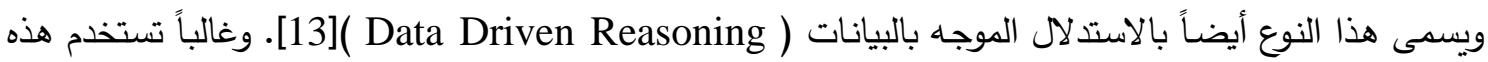
الطريقة في نظم التحليل والتتسير [14] .والثكل (2) يوضح التسلسل المتقدم:

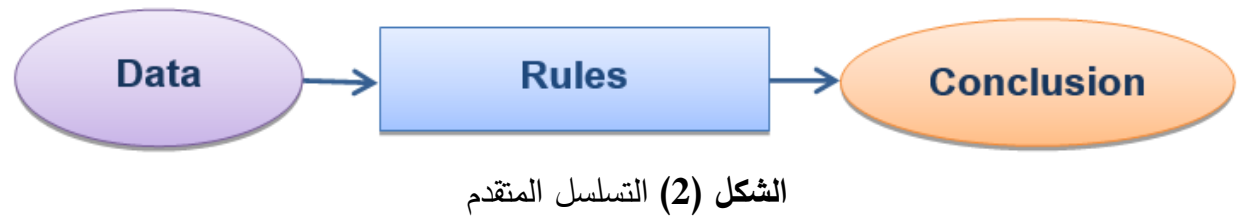

تمثل خوارزمية التسلسل المتقدم Forward chaining algorithm بعدة خطوات وعلى النحو الآتي: - الحقائق الأولية هي مدخلات من المستخدم لتوضع في قاعدة البيانات (الذاكرة العاملة). - تحقق من LHS لقواعد الإنتاج. - إذا تطابق جزء الشرط المنطقي من القاعدة (جزء IF) ، فإن القاعدة "تطلق".

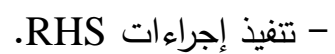
- سحب الشروط / الحقائق القديمة. - إدخال شروط / حقائق جديدة. - القيام بإجراءات المدخلات والمخرجات الأخرى والتوحيد وما إلى ذلك. 
- كرر حتى لا تطلق أي قواعد أخرى.

Backward Chaining التسلسل الراجع

هذه الطريقة تكون عكس الطريقة السابقة، وهي عادةً ترجع من الهدف إلى المسار المؤدي إلى الهدف. وهذه

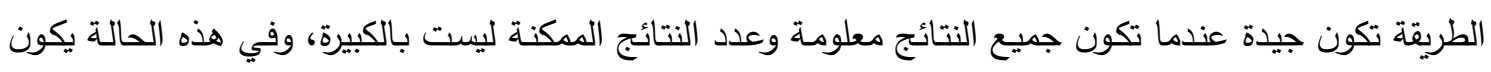
الهدف محدداً والنظام الخبير يحاول تحديد أي الثروط مطلوبة للوصول إلى الهدف المحدد [13]؛ إذ إنَّ الأسلوب

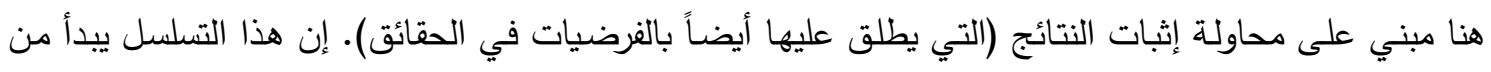

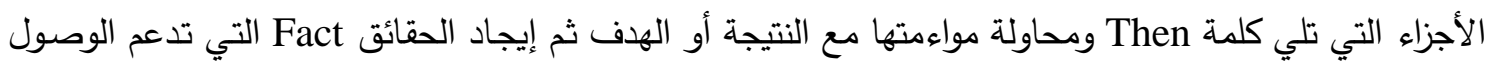
إلى الهدف؛ ولذا يطلق على هذا الأسلوب بالاستدلال الموجه للهدف (Goal Driven Reasoning). وغالباً تستخدم هذه الطريقة في التشخيص [12]. والثكل (3) يوضى لــ التسلسل الراجع:

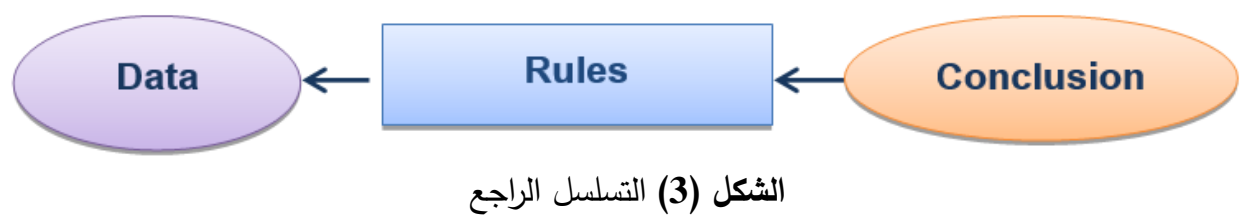

إن اختيار الطريقة المناسبة من إحدى الطريقتين السابقتين تعتمد على الدراسة التي يقوم بها خبير المجال

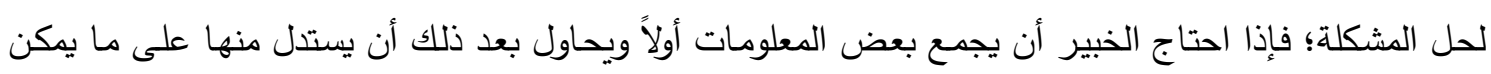

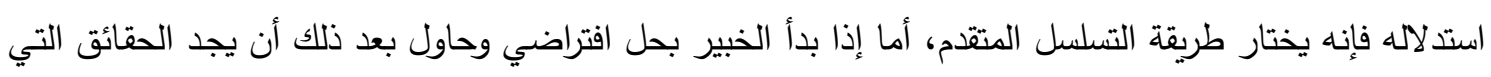
تثبته فإنه يختار طريقة التسلسل الراجع [12]. يمكن تمثيل خوارزمية التسلسل الراجع Backward chaining algorithm على النحو الآتي:

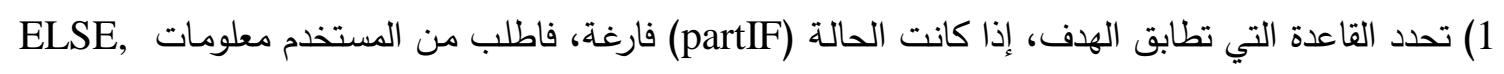
DO لا تتنهي، سوف نختار القاعدة WHILE 2) إضافة شروط القواعد إذا لم يستوفت الشرط THEN، فضع الشرط END WHILE كهدف لحلها [1]].

5atching in forward chaining المطابقة في التسلسل المتقدم

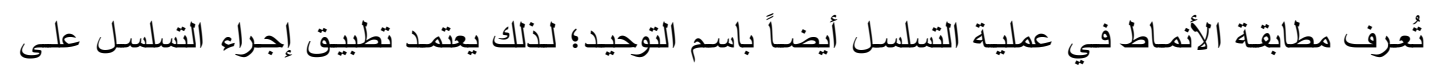

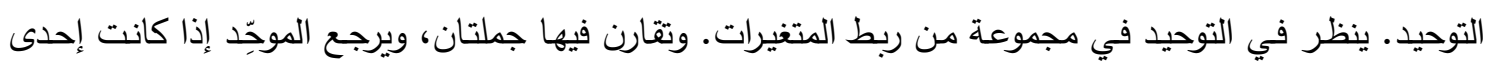

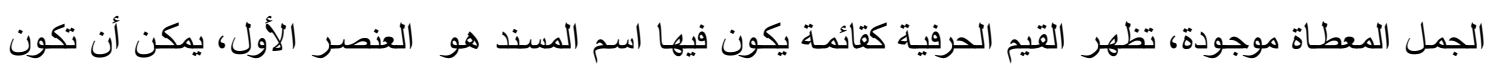

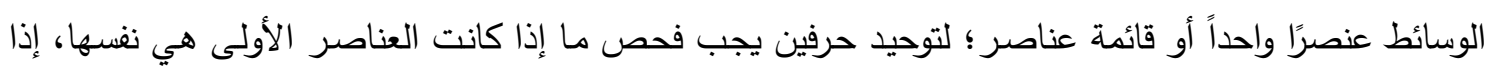

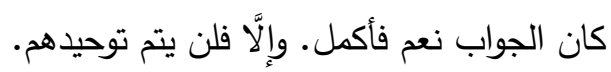

Rule1: if " fact $a=5$ and fact $b=7$ ", فيما يلي مثال بسيط للتسلسل المتقدم:

Then " (fact c=1)"

Rule2: if " (fact c=10) and (fact $d=12)$ ",

Then "(fact $\mathrm{e}=15)$ "

Rule3: if " (fact e=15)",

Then " (fact $\mathrm{f}=18$ )" 
الحقائق التالية موجودة: A=5 ، B=7 ، D=12. تساعد قيم A و على استتتاج قيمة C من القاعدة 1، ثم

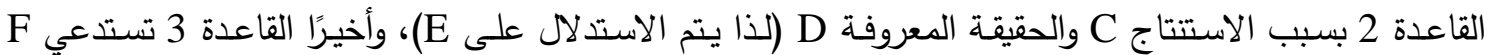

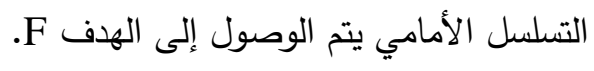
حل المشكلة هو مطابقة القواعد مـع الحقائق واحدة تلو الأخرى على نوح شامل فضـلاً عن استخدام تقانات التسلسل المتقدم والتسلسل الراجع، وهي مفيدة جدًا لمطابقة الحقائق مع الأنماط في القاعدة.

Rule1: if " fact a or fact b",

Then "fact c"

Rule2: if "fact $d$ and fact e and fact $f$ ",

then "fact g"

Rule3: if "fact c and fact g",

Then "fact h"

presented

"b, d, e, f"

Goal : "prove h"

وهيكل مثال التسلسل المتقدم (الهدف) موضح بالثكل(4): إثبات B، D، E، E. تقدم الحقائق الآتية:

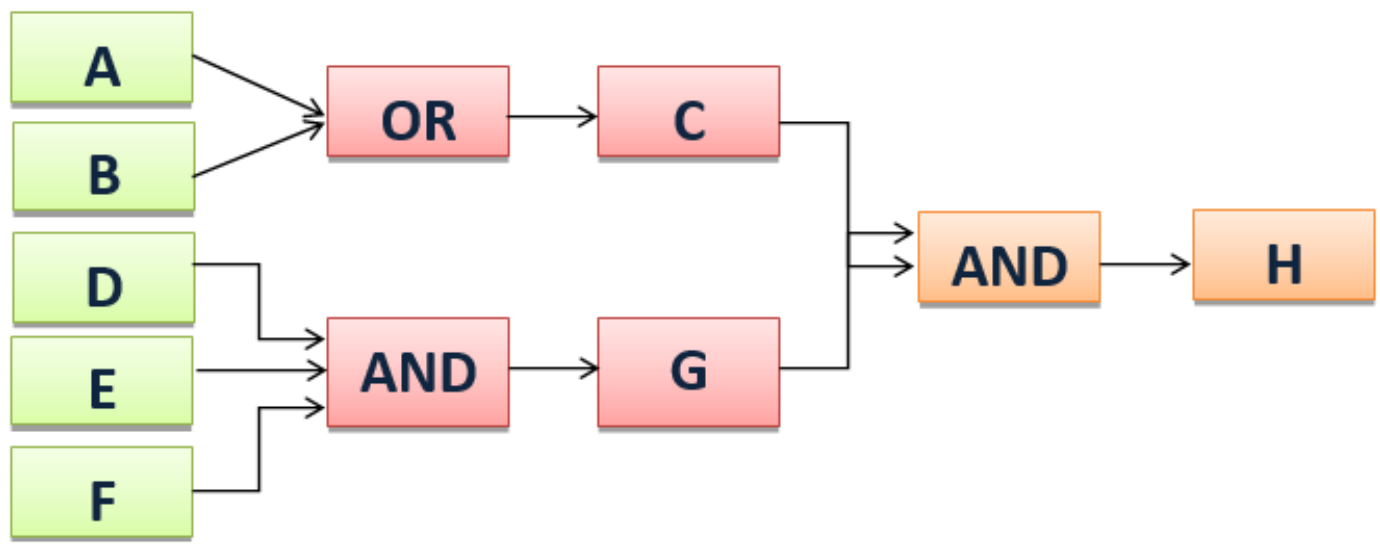

الثكل (4) يوضح تمثيل هيكلية التسلسل المتقدم

6. البحث الأول بعمق في التسلسل المتقدم Depth-first search in forward chaining في بعض الأحيان يمكن تمثيل القواعد في التسلسل المتقدم في شكل شجرة من جذر إلى العمق. فيما يلي

Rule1: if " fact (a) then fact (b)"

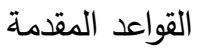

Rule2: if " fact (b) then fact (c) and fact (d)"

Rule3: if "fact (c) then fact (e)"

Rule4: if "fact (d) then fact (f)"

Rule5: if " fact (f) then fact (g) and fact (h)"

يمثل البحث الأول بعمق في التسلسل المتقدم للقواعد المذكورة في الثكل(5). 


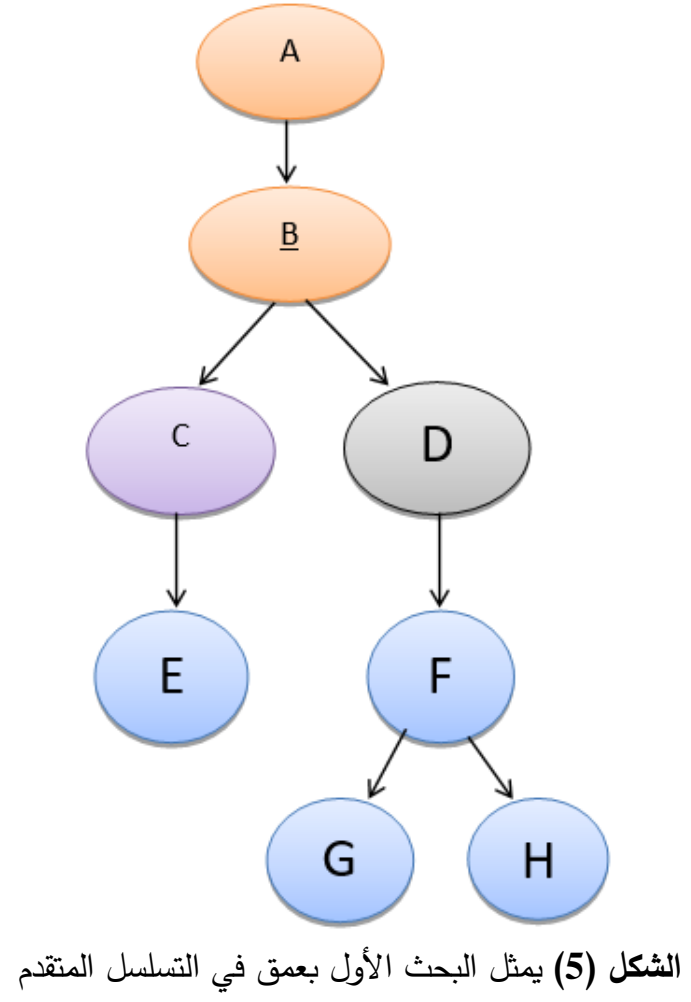

7. البحث الاول بعق في التسلسل الراجع Depth-first search in backward chaining

افترض أن القواعد التالية قد قدمت، وdepth-first backward chaining لهذه القواعد موضحة في الثكل(6). Rule1: if "fact a" and "fact b" and "fact c" then "fact d"

Rule2: if "fact e" and "fact f" then "fact a"

Rule3: if "fact g" and "fact h" then "fact b"

Rule4: if "fact i" or "fact $j$ " then "fact c"

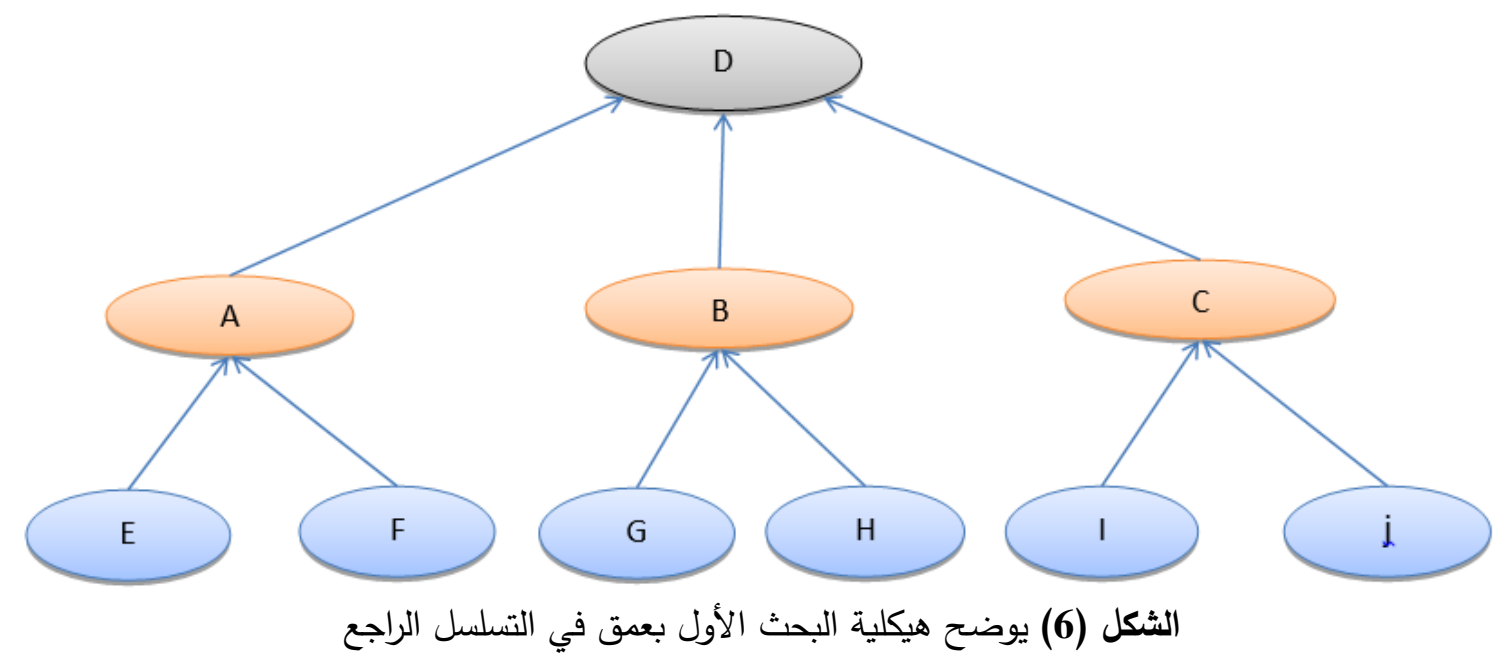

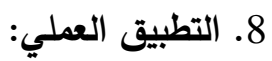

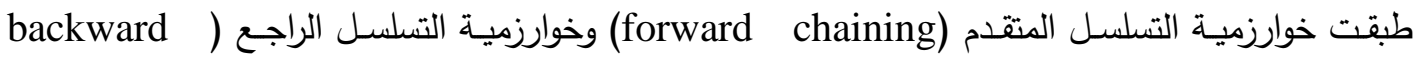

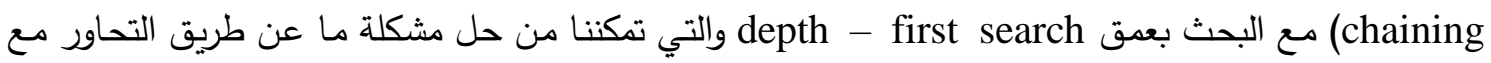

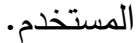


لقد اعتمد على المعرفة المخزونة قاعدة ليستند إليها محرك الاستدلال الذي يتضمن الخوارزميتين المذكورتين أعلاه للتوصل إلى الحلول والإرشادات والتوصيات لتثخيص الحالة المرضية وإعطاء العلاج المناسب لها، واستند في ذلك إلى خبرة الأطباء المختصين ومصادر طبية أخرى؛ إذ إنَّ هذا النظام يستخدمه المستخدمون والمختصون

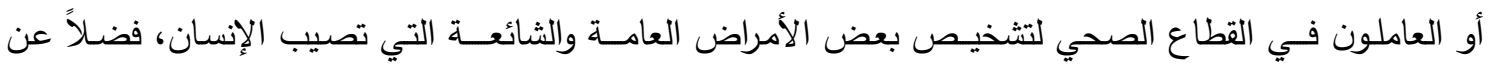

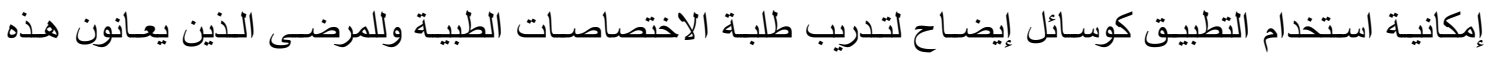

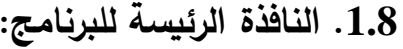

عند تثغيل البرنامج عن طريق الأيقونة الظاهرة على سطح المكتب بعنوان (Doctor) يبدأ البرنامج بالعمل

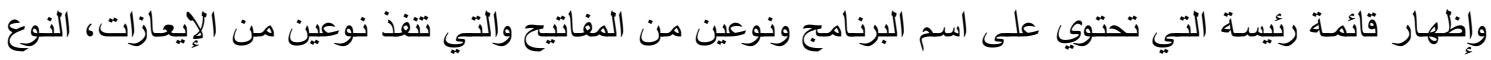

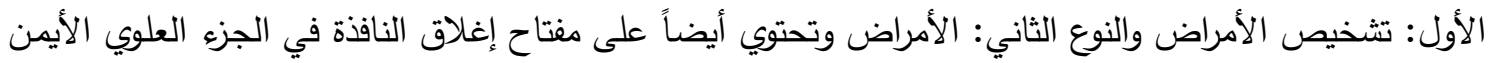

وكما موضح بالثكل(7).

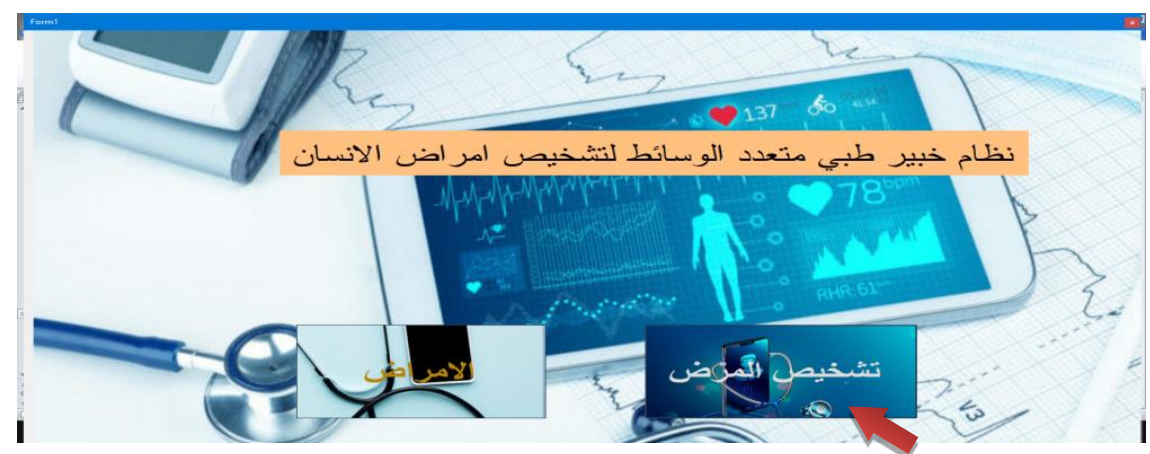

الثكل (7) يوضح القائمة الرئيسة للبرنامج

1.1.8 تطبيق خوارزمية التسلسل المتقدم المتمثلة بتثخيص المرض:

عند الضـغط على مفتاح تشخيص المرض كما مؤشر بالسهم في الثكل (7) ستتفذ خوارزميـة التسلسل المتقدم؛ إذ تظهر لنا نافذة ثانوية باسم: اختر الأعراض، تحتوي على مجموعة من الخيارات التي تمثل الأعراض

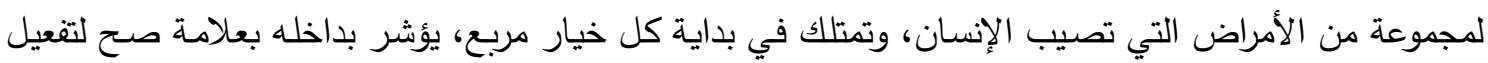

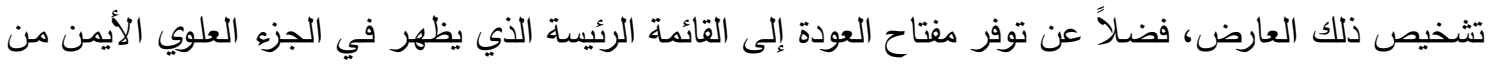

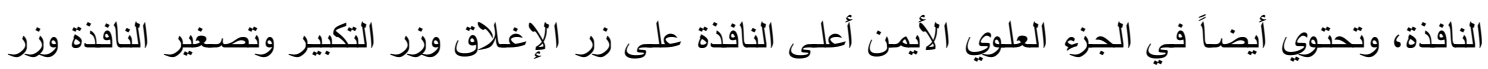

إخفاء النافذة وكما موضح بالثكل(8).

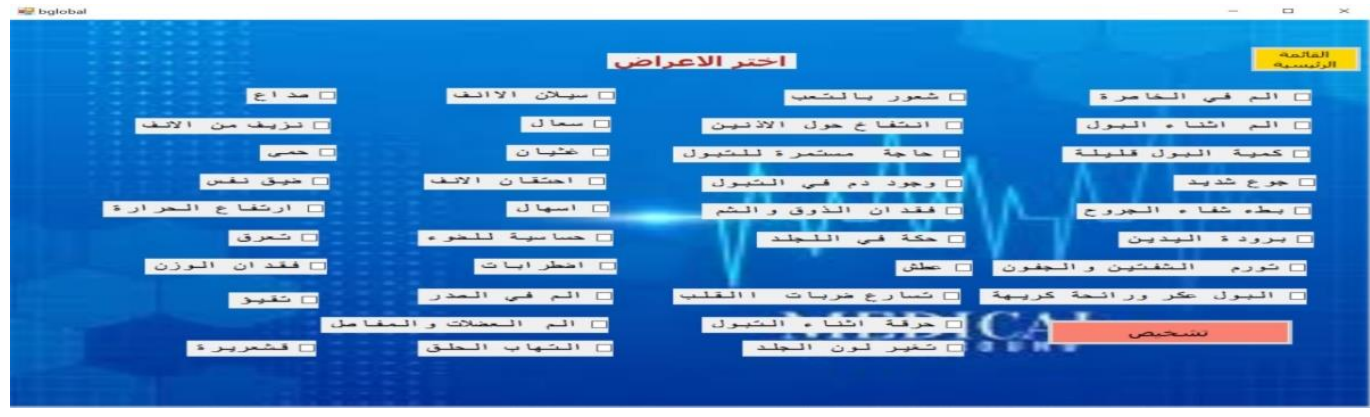

الثكل (8) يوضح محتويات نافذة اختر الأعراض 
عند تفعيل كل عارض ووضـع علامـة صـح في مربع الخيارات وعلى وفق الجدول (1) الذي يوضـح فيـه الأعراض الرئيسة لكل مرض، وضغط مفتاح تشخيص، سوف تظهر لنا نافذة تبين الأعراض والأسباب والوقاية من ون

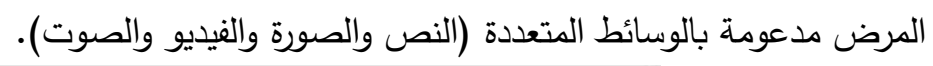

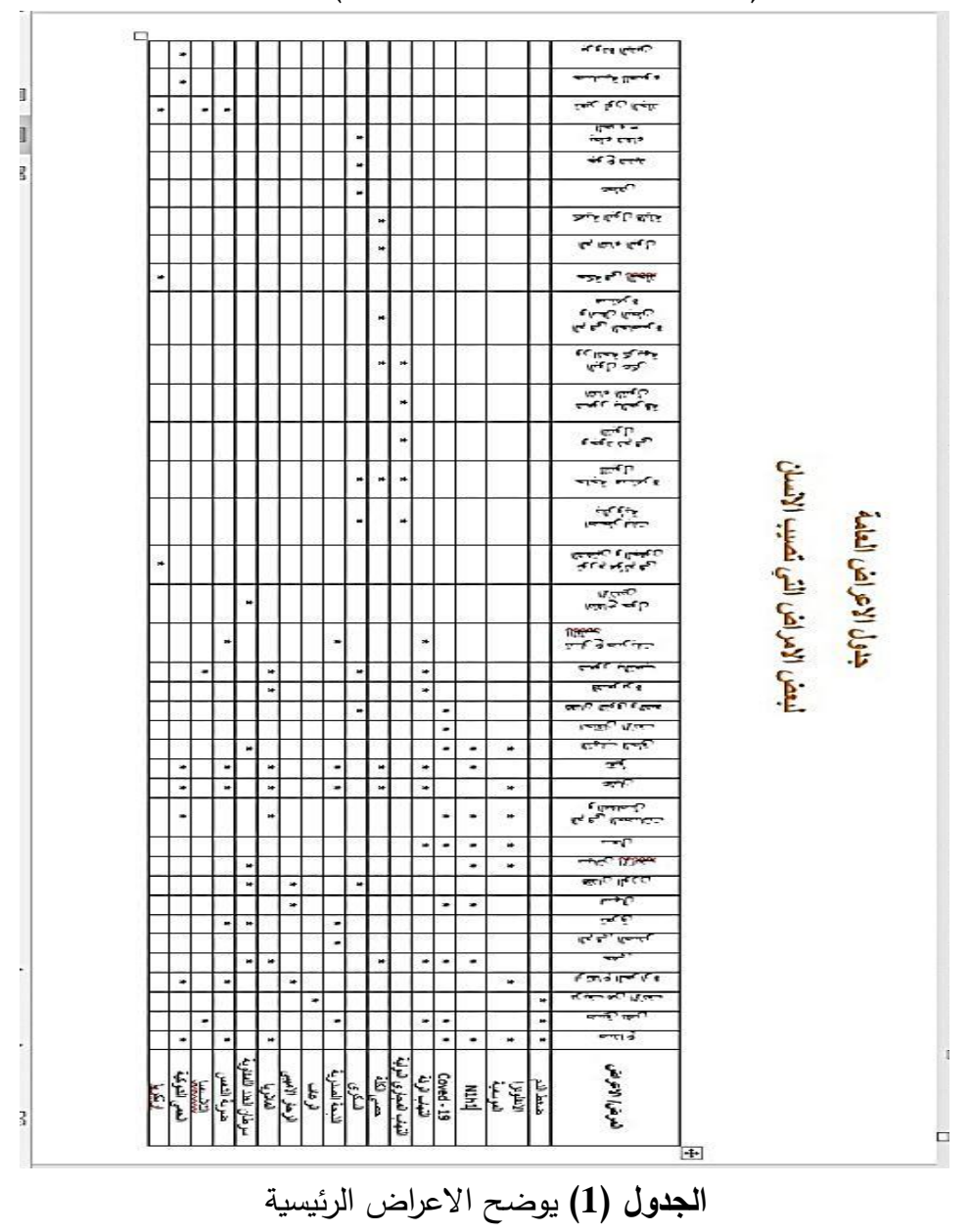

وفي حالة ملء الخيارات على نجو خاطئ والضغط على مفتاح تشخيص سوف يظهر لنا مربع نص يطلب

إدخال الأعراض بدقة وكما في الثكل (9).

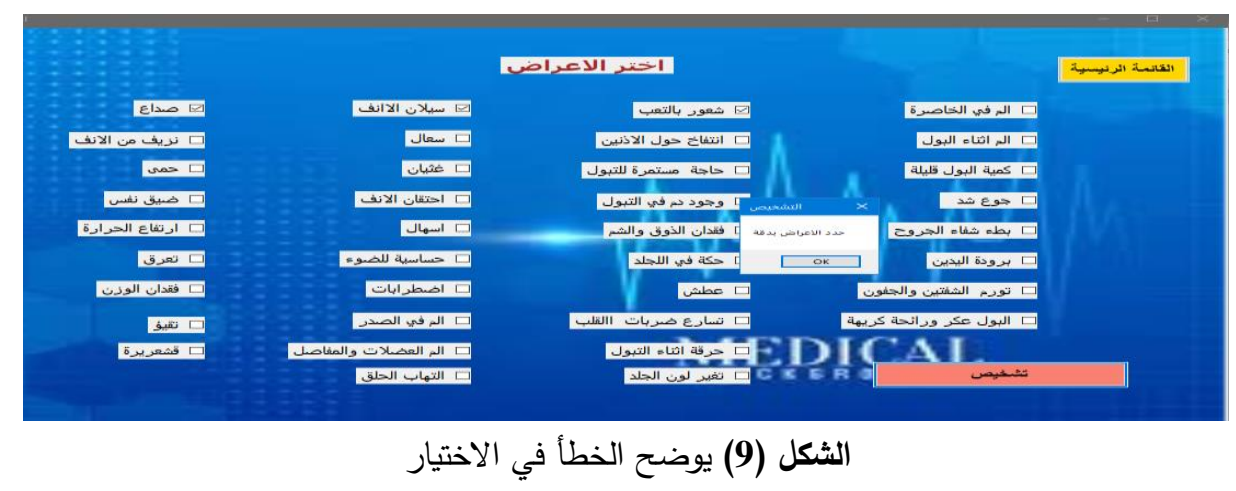

فعلى سبيل المثال لو كان المريض يثكو من أعراض مثل الصداع وضيق بالتنفس ونزيف من الأنف وكما

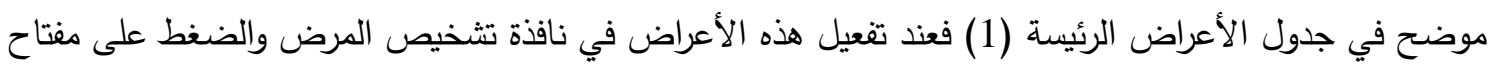
تشخيص وكما موضح في الثكل(10). 


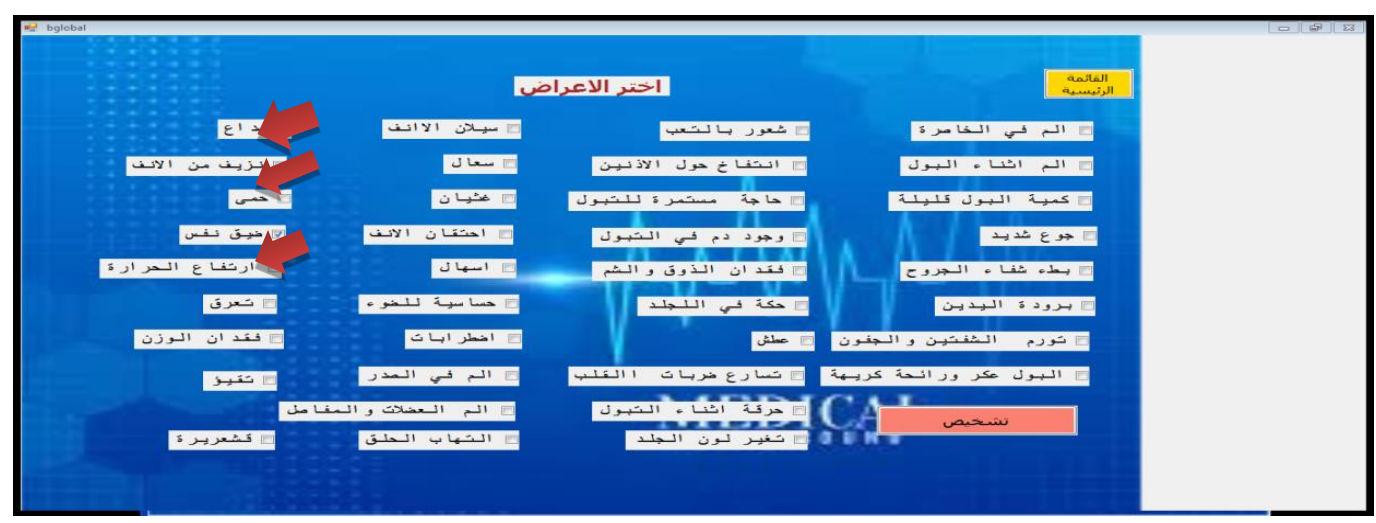

الثكل (10) يوضح كيفية اختيار اعراض ضغط الدم

سوف تظهر لنا نافذة أخرى تحتوي على اسم المرض (ضغط الدم) وصورة توضيحية لشكل الإصـابة بالمرض وكما موضح في الثكل (11).

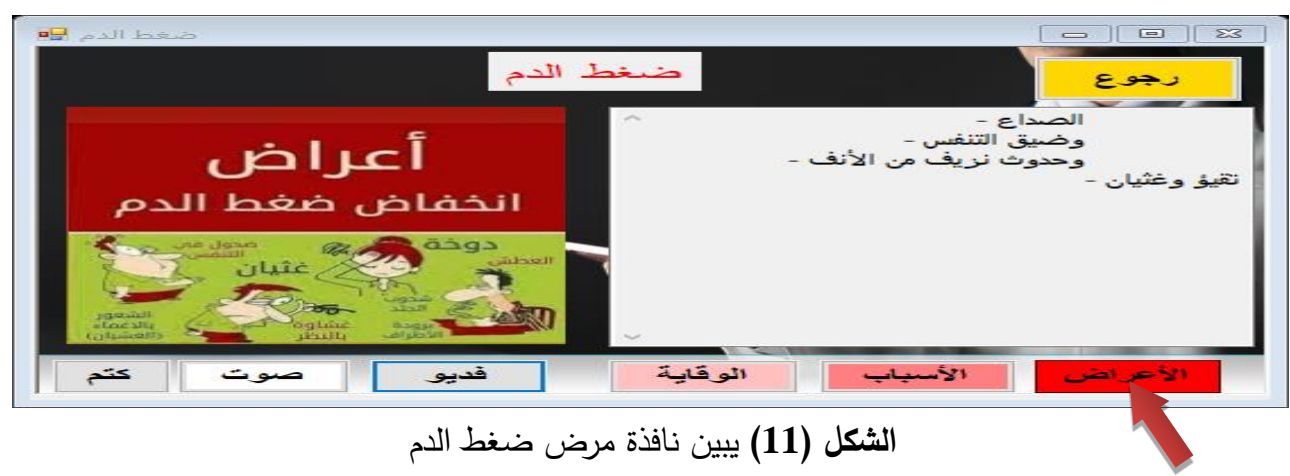

فضلاً عن ذلك تحتوي النافذة على مجموعة من المفاتيح التي تتفذ مهام معينة وكما موضح في أدناه. 1. الأعراض: عند الضغط على مفتاح الأعراض سوف يظهر لنا نص توضيحي يوصف فيه الأعراض التي تظهر

على المريض المصاب بضغط الدم الثكل (11). 2. الأسباب: عند الضغط على مفتاح الأسباب سوف يظهر لنا نص توضيحي يوصف فيه الأسباب التي أدت إلى الإصلابة بمرض ضغط الادم وكما في الثكل (12).

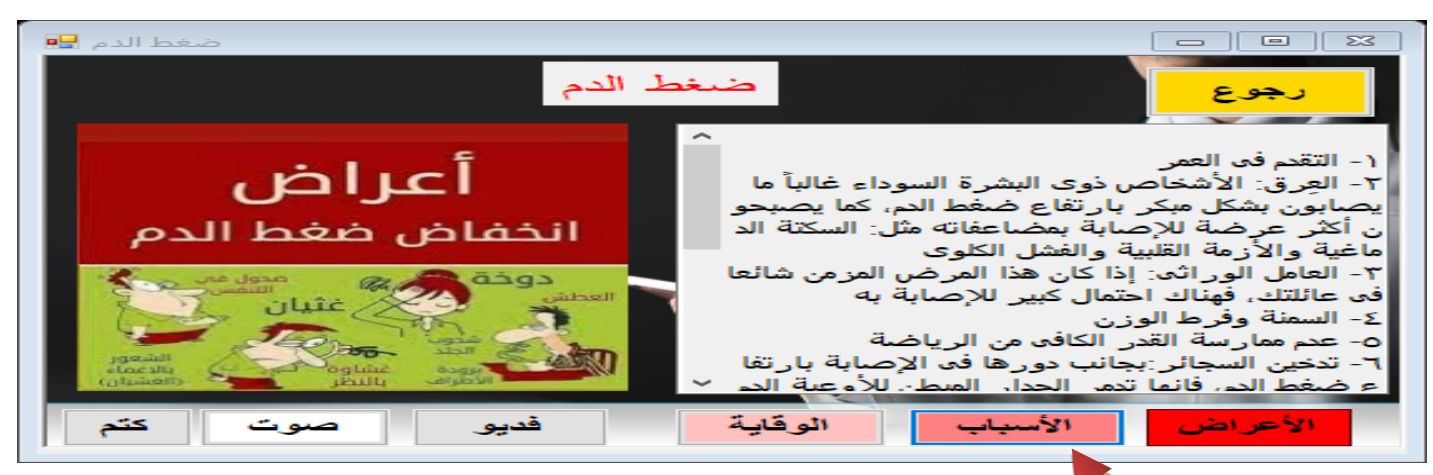

الثكل(12) يوضح نافذة مفتاح اسباب ضغط الدم 
3. الوقاية: عند الضغط على مفتاح الوقاية سوف يظهر لنا نص توضيحي يوصف فيه الإرشادات وطرائق الوقاية

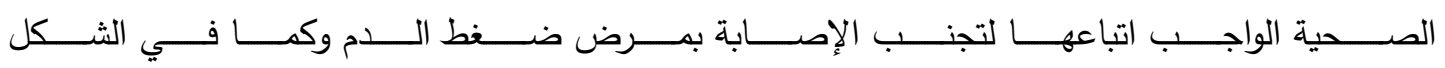

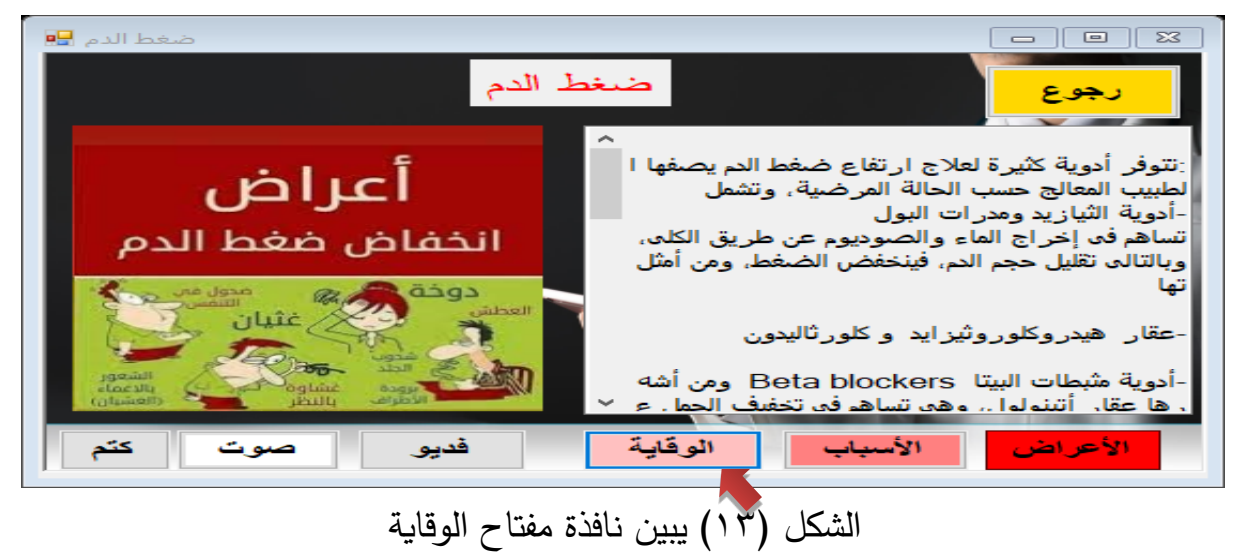

4. فيديو: عند الضغط على مفتاح فديو سوف يظهر لنا تسجيل فديوي (صورة وصوت) يوضحها طبيب إخصائي بمرض ضغط الدم يوصف فيه المرض و أسبابه وطرائق علاجه والإرشادات الصحية الواجب اتباعها للوقاية من الإصابة بهذا المرض وكما في الثكل (14).

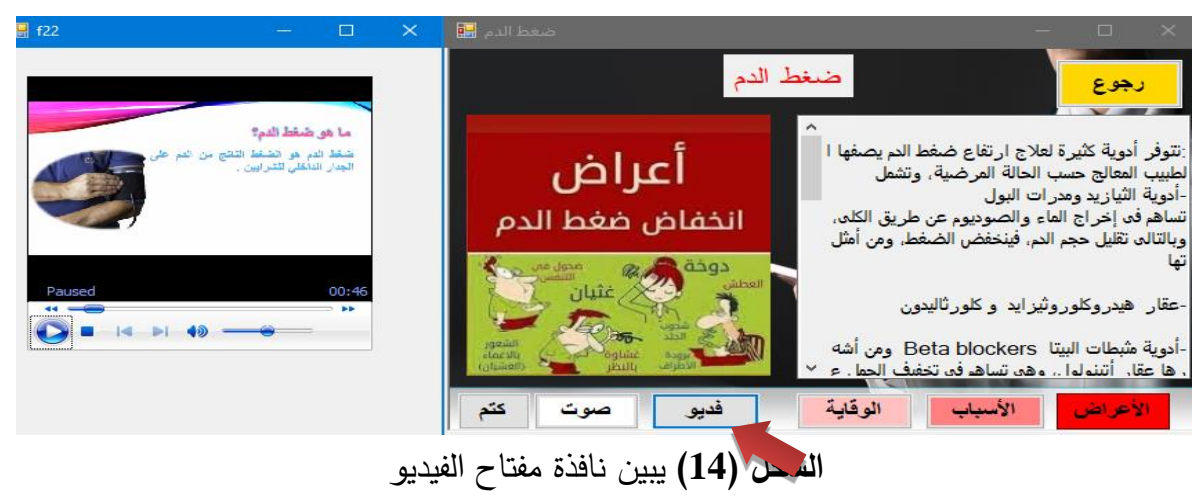

5. الصـوت: عند الضغط على مفتاح الصوت سوف يظهر لنا تسجيل صوتي يوضـح أعراض المرض وأسبابه

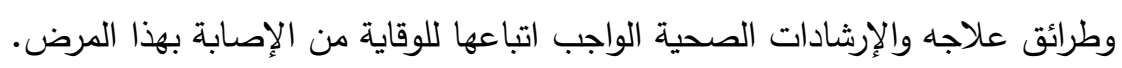

6. كتم: عند الضغط على مفتاح كتم سوف يوقف تثغيل التسجيل الصوتي.

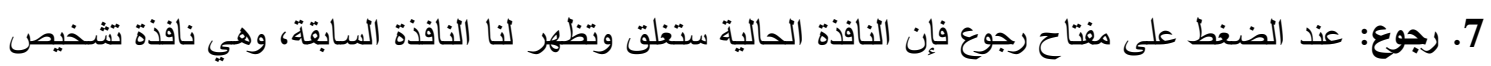
المرض أي الثاشة في الثكل رقم (7).

2.1.8 تطبيق خوارزمية التسلسل الراجع المتمثلة بمفتاح الأمراض:

عند الضغط على مفتاح الأمراض بالثاشة الرئيسة بالثكل رقم (7) سوف تظهر لنا نافذة ثانوية تحتوي على مجموعة من المفاتيح التي تتضمن بعض الأمراض التي تصيب الإنسان فضـلاً عن مفتاح القائمسة الرئيسة للعودة

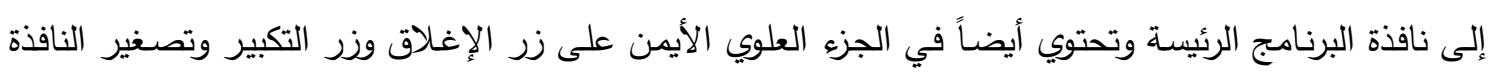
وزر إخفاء النافذة وكما موضح بالثكل (15). 


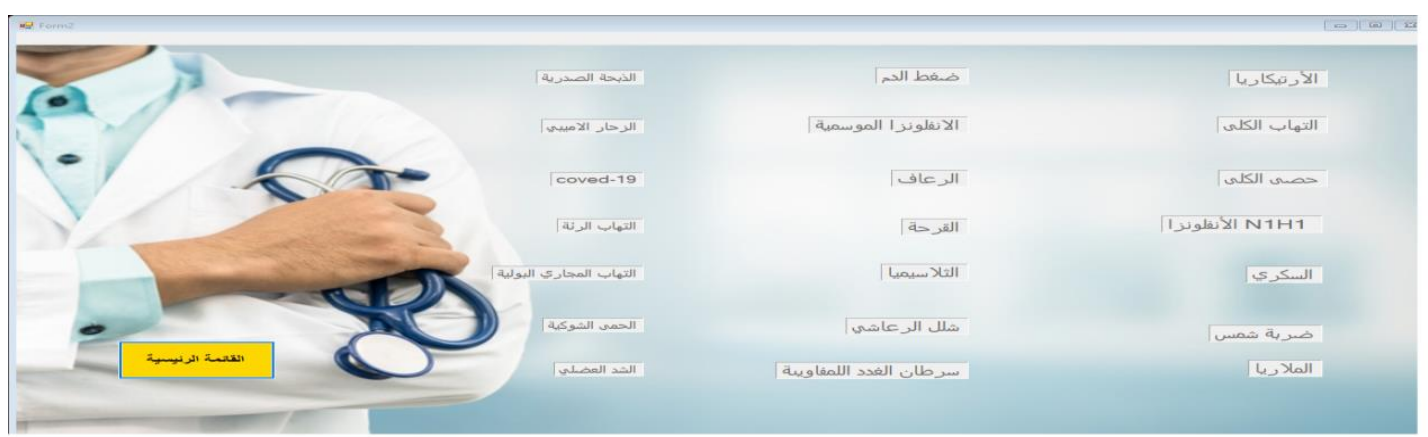

الثكل (15) يوضح محتويات نافذة الامراض

وهنا تتفذ خوارزمية التسلسل الراجع؛ إذ عند الضغط على أحد المفاتيح الموجودة في نافذة الأمراض والخاص بمرض معين مثل (كوفيد- 19) سوف تظهر لنا نافذة تحتوي على اسم المرض وصورة توضيحية لشكل الإصـابة

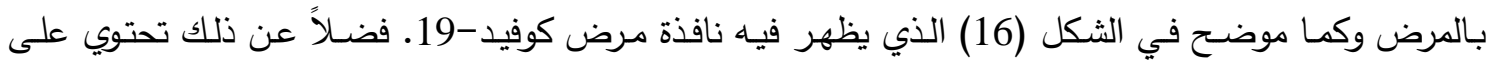
مجموعة من المفاتيح والتي تتفذ مهام معينة وكما موضح في في أدناه.

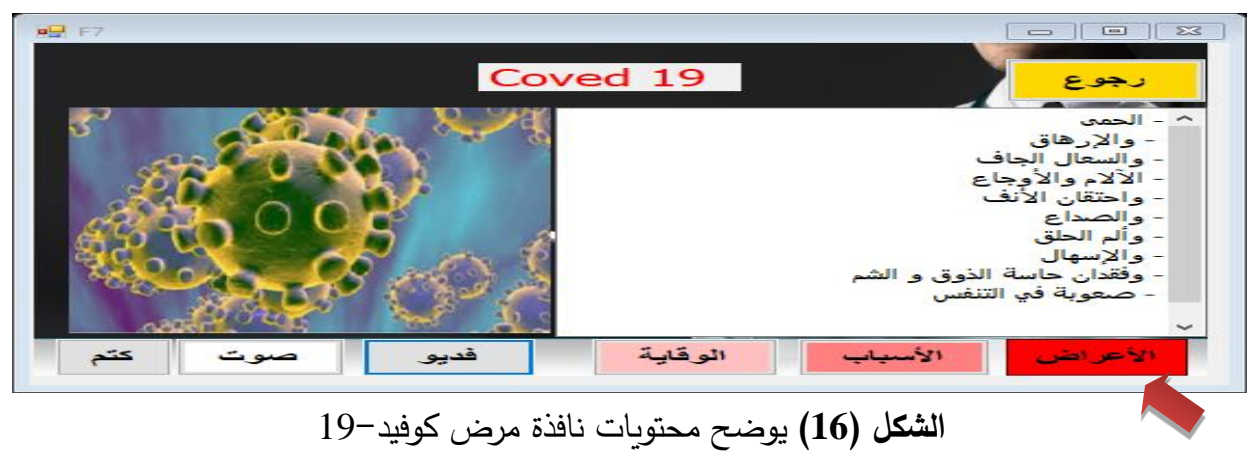

1- الاعراض: عند الضغط على مفتاح الأعراض سوف يظهر لنا نص توضيحي يوصف فيه الأعراض التي تظهر على المريض وكما موضح في الثكل أعلاه. 2- الأسباب: عند الضغط على مفتاح الأسباب سوف يظهر لنا نص توضيحي يوصف فيه فئ الأسباب التي أدت إلى الإصابة بالمرض وكما موضح في الثكل (17).

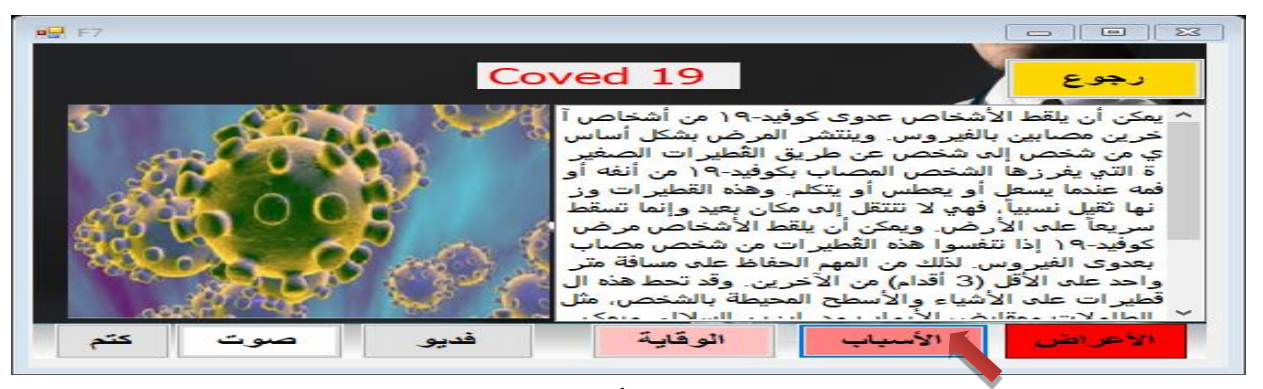

الشكل (17) يبين نافذة الأسباب لمرض كوفيد-19

3- الوقاية: عند الضغط على مفتاح الوقاية سوف يظهر لنا نص توضيحي يوصف فيه الإرشادات وطرائق الوقاية

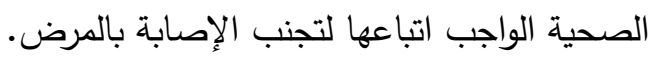


4- فيـليو: عند الضـغط على مفتـاح فديو سـوف يظهر لنـا تسجيل فديوي (صـورة وصـوت) يوضـحها طبيب

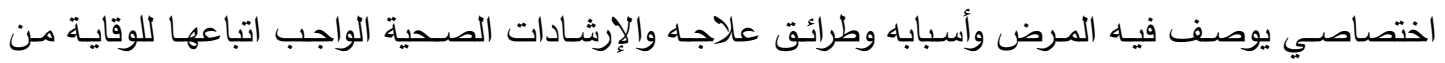

الإصابة بهذا المرض كما في الثكل رقم (18).

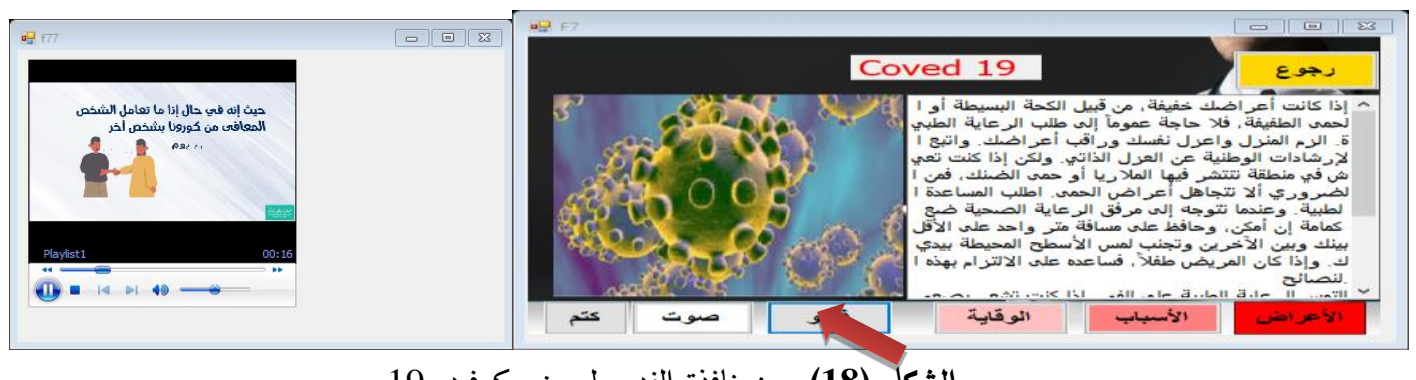

الثكل (18) يبين نافذة الفديو لمرض كوفيد-19

5- الصسوت: عند الضغط على مفتاح فديو سوف يظهر لنا تسجيل صوتي يوضحه طبيب اختصاصسي أعراض

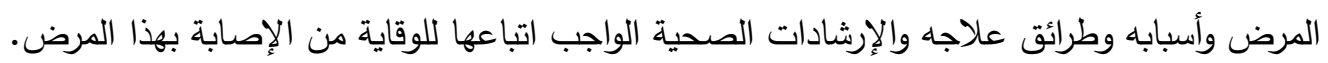

6- كتم: عند الضغط على هذا المفتاح سوف يتم يوقف تثغيل التسجيل الصوتي.

ويتضمن البرنامج مجموعة وافرة من الأمراض التي تتفذ بخوارزميتي التسلسل الأمامي والتسلسل الخلفي ونذكر منها ما يأتي:

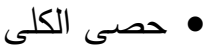

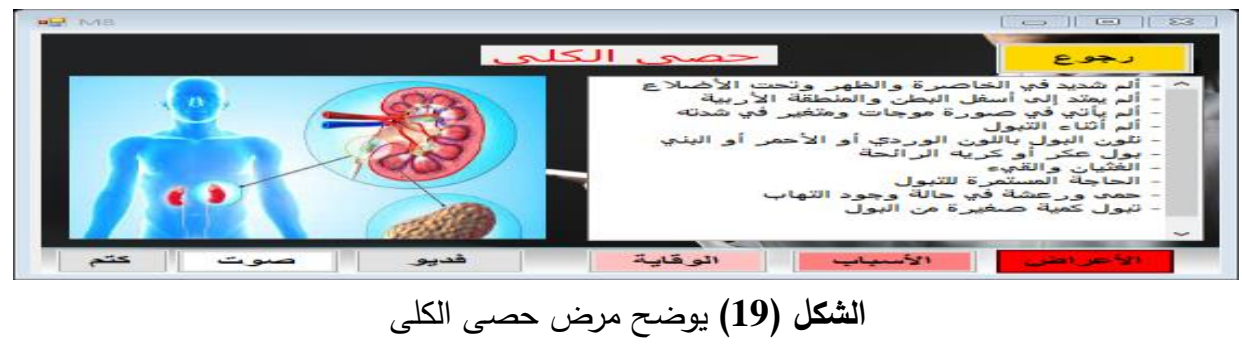

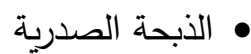

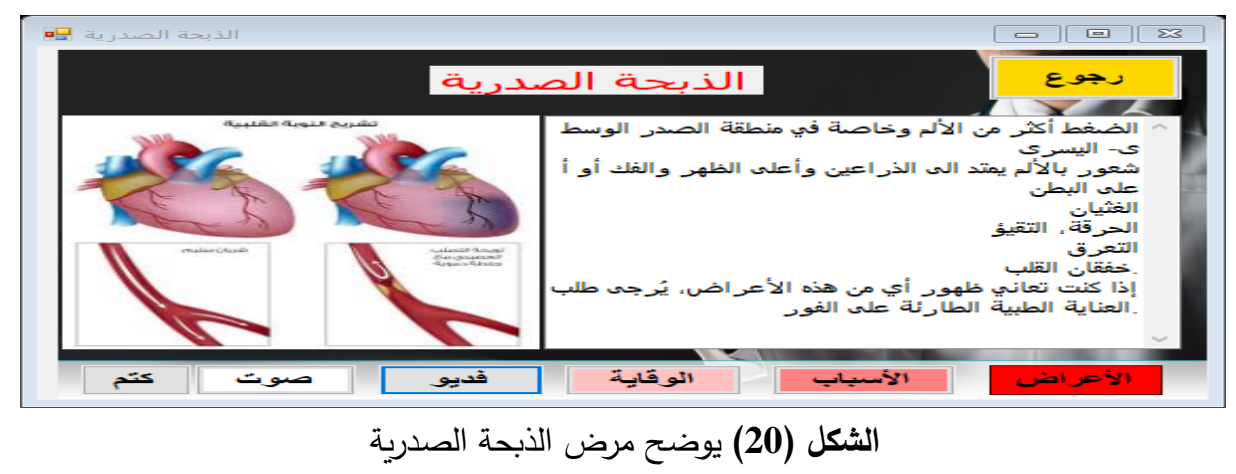




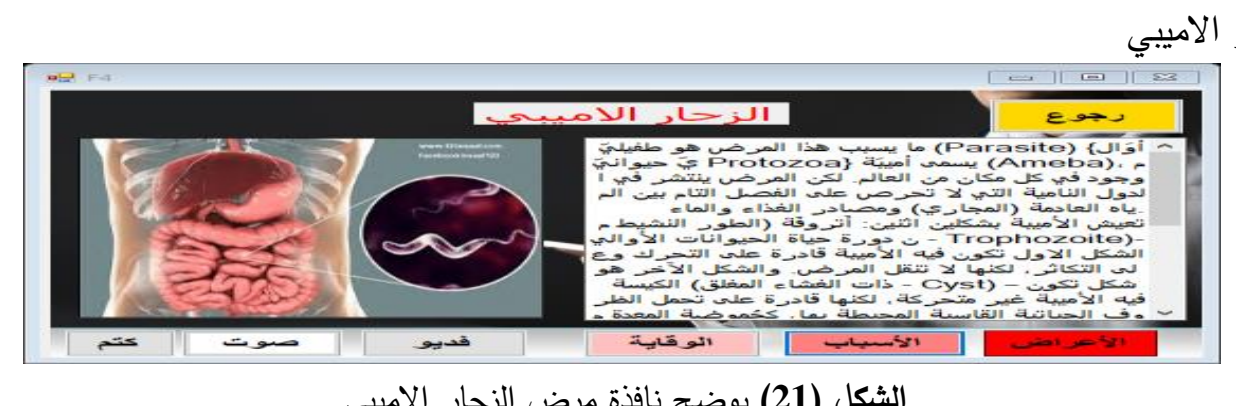

$$
\text { الثكل (21) يوضح نافذة مرض الزحار الاميبي }
$$

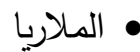

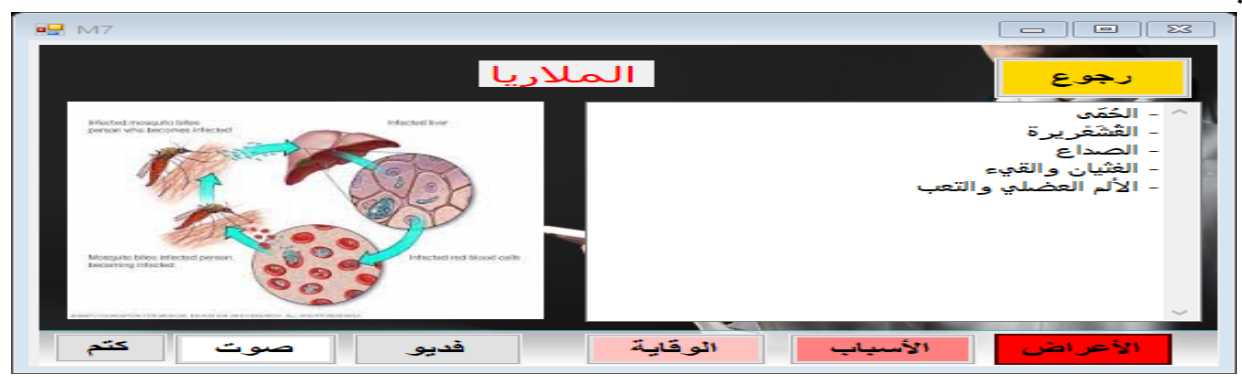

الثكل (22) يوضح نافذة مرض الملاريا

في هذا البحث بني نظام خبير متعدد الوسائط؛ إذ يحتوي على (نص، صورة، صوت، فيديو) لتشخيص

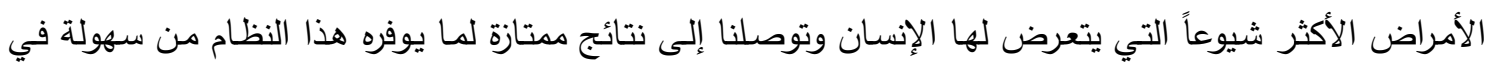

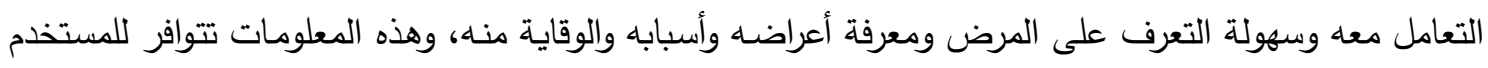

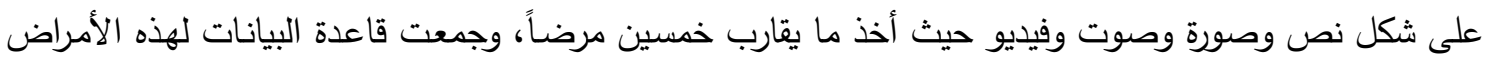

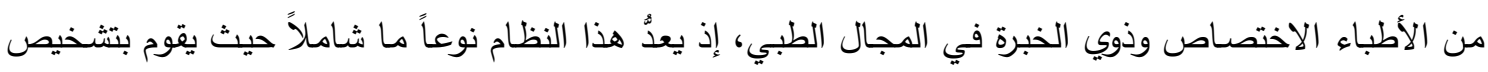

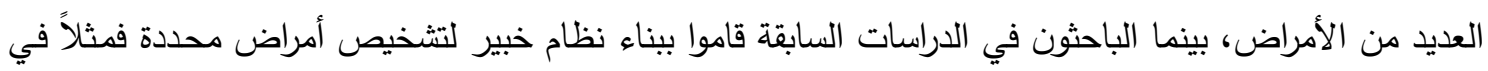
المصدر رقم 8 قام الباحثون ببناء نظام لتشخيص أمراض الالتهاب الرئوي، وفي المصدر رقئم 5 استخدم التباء الباحثون

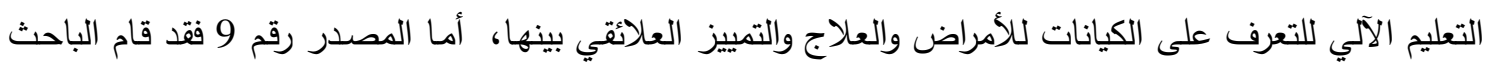

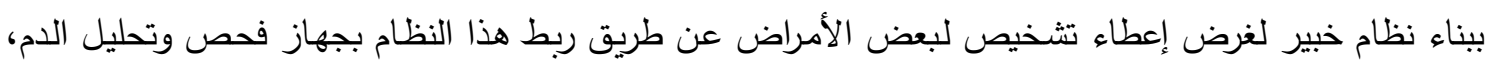
أما الباحث في المصدر رقم 10 فإنه قام ببناء نظام خبير لتشخيص الأمراض الباطنية.

\section{9.}

عند تنفيذ وتطبيق خوارزميات التسلسل الامـامي والتسلسل الراجع (الخلفي) Forward chaining and)

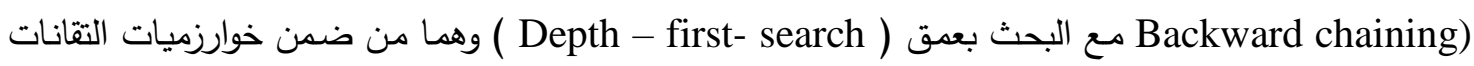
الذكائية، هناك بعض الاستتتاجات التي تم التوصل إليها وهي: 1. 1 تثخيص الأمراض بأقل وقت وأقل جهد. 2. الدقة العالية في تثخيص الأمراض مما يجعل الأخطاء الطبية قليلة. 3. يقوم النظام الخبير بتثخيص الأمراض على نحو مستمر وبدون جهد أو ملل. 4. مدكن أن يحل النظام الخبير محل الطبيب في الحالات الطارئة في حالة غياب الطبيب المختص. 5. وحصلت على مستوى أداء عالٍ في التشخيص والاطلاع على الأمراض التي تصيب الإنسان. 


\section{المصادر}

د.سامية شهيبي قمورة، باي محمد، حيزية كروش، 2018، "الذكاء الاصطناعي بين الواقع والمأمول،

$$
\text { دراسة تقنية وميدانية" الملتقى الدولي. }
$$

[2] Turban, Efram, et al., 2007, "Decision Support and Business Intelligence Systems", $8^{\text {th }}$ ed., Pearson Prentice Hall, New Jersey- USA, Pp. 540, 535, 537538.

[3] Bruce G. Buchanan ,1992, Addison- " Wesley Series in Artificial Intelligence" Department of computer science Stanford University Edward H. Shortliffe Department of Medicine Stanford University School of Medicine

[4] Jha,Saurabh,andEricj .topol,(2018), "Information and Artificialintelligence," jornal of the American college of Radology 15.3:509-511

[5] Razavan c. Bunuesu and Raymond j. Mooney, 2005, "Shortest path dependency kernel for relational extraction" human language technology conference on empirical method natural language processing. pp. 724-731.

[6] Barlow j., Dennis R., (2016), "notas smart as wethink:Astudy of the American Collective Intelligence in Virtual groups", journal of manage ment information systems, vol.33(3),pp684-712.

[7] AruOkerekeEze and opera F.K An, 2012, "Expert System (Autodoc) for diagnosing diseases and prescribing medication using visual basic.net ", Department of Electrical/Electronic Engineering, Federal University of Technology, Owerri, Imo state, Nigeria information technology Research Journal Vol. 2(2), Pp. 20-24.

[8] Rajpurkar,2020,"CheXNet: Radiologist-Level Pneumonia Detection on Chest XRays with Deep Learning". $\underline{\text { arXiv } . ~}$

2013," Building Expert System for the Diagnosis of Internal عمر احمد حامد"

$$
\text { رسالة ماجستير ,كلية علوم الحاسوب وتقانة المعلومات. Diseases", }
$$

[10] Ibraheem Nadher Ibraheem, 2018, "Construction and Implementation of an Expert System for Medical Diagnosis Based on Blood Test", Tikrit Journal of Pure Science 23 (10) 2018. pp. 110-117

[11] Y. Dupy, M. Kalika, 1989, "les systèmes de gestion”, vuibert P 120.

[12] Deshpande, Neeta, 2008, "Artificial Intelligence", 2nd Revised Edition 2008.

[13] Badiru, Adedeji B. and Cheung John Y., 2002, "Fuzzy Engineering Expert Systems with Neural Network Application", John wiley \& sons Inc., New York USA.

[14] Mark, v., Nerode, A., Remmel B., (1994), "A context for belief revision: forword chaining- normal nonmotonic rule systems", annals of pure and applied logic, vol 67. 